\title{
The Effect of Brief Mindfulness Meditation on Cold-Pressor Induced Pain Responses in Healthy Adults
}

\author{
David Burnett, Gillian Phillips, Osama A. Tashani* \\ School of Clinical and Applied Sciences, Leeds Beckett University, Leeds, United Kingdom \\ Email: ${ }^{\star O}$.Tashani@Leedsbeckett.ac.uk
}

How to cite this paper: Burnett, D., Phillips, G. and Tashani, O.A. (2017) The Effect of Brief Mindfulness Meditation on ColdPressor Induced Pain Responses in Healthy Adults. Pain Studies and Treatment, 5, 1119.

https://doi.org/10.4236/pst.2017.52002

Received: March 9, 2017

Accepted: April 25, 2017

Published: April 28, 2017

Copyright ( $) 2017$ by authors and Scientific Research Publishing Inc. This work is licensed under the Creative Commons Attribution International License (CC BY 4.0).

http://creativecommons.org/licenses/by/4.0/ c) (i) Open Access

\begin{abstract}
We hypothesised a 10 minute mindfulness based intervention performed by a novice therapist would have a beneficial effect on pain responses in naive participants. Twenty-four participants were randomly assigned to the control group or mindfulness meditation group. The control group sat quietly for 10 minutes in between two cold pressor tasks. The mindfulness meditation intervention group practiced 10 minutes of mindfulness meditation in between cold-pressor tasks following standardised mindfulness of breathing meditation technique instructions provided by a male investigator. A significant interaction effect was found between anxiety towards pain ratings (pre-intervention vs. post-intervention) and intervention $(\mathrm{F}=6.29, \mathrm{p}=0.02)$. There was a significant decrease $(t=4.07, p=0.002)$ in anxiety towards pain ratings in the mindfulness meditation group following intervention. A significant interaction effect was found between pain threshold times (pre-intervention vs. post-intervention) and intervention $(\mathrm{F}=18.45, \mathrm{p}<0.001)$. There was a significant increase $(t=-4.38, p=0.001)$ in pain threshold times in the mindfulness meditation group following intervention. A significant interaction effect was found between pain tolerance times (pre-intervention vs. post- intervention $)$ and intervention $(\mathrm{F}=18.34, \mathrm{p}<0.001)$. A significant increase $(\mathrm{t}=$ $-4.20, p=0.001)$ in pain tolerance times in the mindfulness meditation group following intervention was also found. The results suggest a single 10 minute mindfulness meditation intervention administered by a novice therapist can improve pain tolerance, pain threshold and decrease anxiety towards pain in naïve healthy university aged individuals.
\end{abstract}

\section{Keywords}

Mindfulness, Pain, Cold-Pressor Task, Brief Session, Pain Relief 


\section{Introduction}

An increasing interest in the clinical use of mindfulness meditation has led to a surge in recent research that has indicated mindfulness based interventions to be an effective treatment of numerous physical and psychological illnesses [1]. Although mindfulness based interventions are not standardized, mindfulness can be defined as "a set of techniques designed to encourage deliberate, non-evaluative contact with events that are here and now" [2]. Mindfulness meditation can cultivate awareness of the present moment, maintain attention on a single aspect without bias, and encourage detachment from emotions, thoughts, beliefs and any particular outcome [3].

There is a considerable body of research that supports the benefits of mindfulness meditation on pain [1] [3] [4] [5]. Pain can limit movement, function, motivation and psychological well-being of an individual, which are all key factors in the success of the rehabilitation process [6]. Mindfulness meditation can modulate the experience of pain or improve a patients' ability to cope with pain [6]. Attenuation of pain symptoms is seen in experienced meditators and in subjects after many hours of guided practice by experienced meditators [1]. In the clinical setting, patients will not have access to experienced meditators or the time to participate in lengthy mindfulness based interventions. Limited research has explored whether the beneficial effects of mindfulness meditation demonstrated by experienced meditators or many hours of practice can be seen in untrained individuals after a brief intervention.

Most clinicians will have little to no experience in mindfulness meditation training. Presently, the effects of a brief intervention administered to both genders by a therapist without years of mindfulness meditation training experience are unclear. If a brief mindfulness based intervention can replicate the positive effects on pain shown in experienced meditators and longer mindfulness based interventions it could benefit patients and clinicians attempting to improve patients' rehabilitation process and overall well-being.

Our study examined the effects of a single, brief session of mindfulness meditation on multiple aspects of the pain experience.

\section{Methods}

This study was approved by the local ethics committee at the Faculty of Health and Social Sciences, Leeds Beckett University and the Ethical Guidelines of the International Association for the Study of Pain were strictly followed during recruitment and conduct of the experiments which lasted from December 2014 to February 2016.

\subsection{Participants}

A power calculation using Harvard University online calculator

(http://hedwig.mgh.harvard.edu/sample_size/size.html) revealed that a total of 24 patients should enter this two-treatment parallel-design study. The probabili- 
ty is 90 percent that the study will detect a treatment difference at a two-sided 0.05 significance level, if the true difference between treatments is 1.389 times the standard deviation. To be recruited participants had to be over 18 years of age. All participants completed an eligibility form to ensure they were healthy and pain free. Informed consent was gained from each participant prior to data collection. A self-exclusion screening form was completed by all participants to ensure the absence of factors that could contribute to altered pain perception. These factors included use of any medication, skin sensation disturbances and previous meditation experience. Following standard convention for the coldpress or task, participants that could maintain their hand in the ice water for 3 minutes were excluded from the study. No participants were excluded from the study. All participants completed the study. The final sample contained twenty-four participants, twelve female participants with the average age of 24.25 (SD $=1.21$ ) and twelve male participants with an average age of 24.58 ( $\mathrm{SD}=2.11$ ). The participants were randomly divided into a control group or a mindfulness meditation group containing equal numbers of males and females.

\subsection{Cold-Pressor Task}

The cold pressor-task is a reliable and valid method for inducing pain [7]. It has also been shown to generate a reproducible onset of pain sensation and cause an aching pain of a similar clinical nature and intensity [8] [9]. Every participant was provided a familiarisation session to introduce the cold-pressor task and allow participants to get comfortable with the task. A crib sheet with succinct instructions on how to perform the cold-pressor task was used for every participant and every cycle. The cold-pressor apparatus involved two basins. One contained warm water at $36^{\circ} \mathrm{C}-37^{\circ} \mathrm{C}$. The other contained cold water and ice between $0^{\circ} \mathrm{C}-2^{\circ} \mathrm{C}$. Before the cold-pressor task, participants placed their hand in the warm water for 2 minutes to maintain a baseline temperature. Their hand was then moved immediately into the ice water. Participants attempted to keep their hand submerged in the ice water for as long as possible. When the pain could no longer be tolerated, participants removed their hand from the ice water.

\subsection{Mindfulness Meditation Intervention}

The mindfulness meditation instructions were read to each participant word for word by the same researcher. The researcher did not have any previous mindfulness meditation training experience. The instructions represent a brief introduction to the mindfulness of breathing mediation technique where an individual focuses their attention and awareness toward their own breathing. This simple practice is based upon traditional Buddhist teachings from the Anapanasati Sutta [10]. After the instructions were read, the participants were encouraged to meditate for the remaining 10 minutes. The mindfulness meditation instructions were as follows:

- You might feel funny for a bit. If you need to open your eyes at any point feel free but bring your attention back to the mindfulness meditation. 
- Once I am done with the instructions, I will leave you to mindfully meditate for 10 minutes.

- Sit as comfortable as possible with good posture, feet flat on the floor and your hands folded in your lap.

- Direct your attention to the flow of your breath. Deeply inhale and exhale a few times. Feel your chest and rib cage opening. Feel your shoulders lifting slightly on the inhale and lowering on the exhale.

- Now let your breathing return to normal. Let your shoulders relax.

- Close your eyes... relax your eyes... relax your face... relax your shoulders... relax your stomach.

- Experience your breath naturally as it comes into your body and comes out again. With each breath you become more relaxed. Experience each breath as it comes... with each breath being different from the next.

- Simply experience the present moment of each breath. Be aware of the breath coming in and aware of the breath coming out. If your attention wanders from your breath because of the noise or anything else simply bring it back.

- When experiencing a feeling or a thought, notice these thoughts and emotions not as fact but observe them as an inner experience.

- Continue to experience each breath coming in and coming out bringing your attention back to your breathing any time you are distracted...

\subsection{Procedure}

The study was led by the same researcher in the same University laboratory room for all participants. Participants were randomly allocated to the control intervention or mindfulness meditation intervention groups. Participants in both groups underwent a pre-intervention cycle of the cold-pressor task and a post-intervention cycle of the cold-pressor task separated by a 10 minute interlude. The control intervention group sat quietly for 10 minutes in between coldpressor tasks. The mindfulness meditation intervention group practiced $10 \mathrm{mi}-$ nutes of mindfulness meditation following brief instructions provided by the researcher in between cold-pressor tasks. The 10 minute interval between coldpressor task interventions assisted to control for diffuse noxious inhibitory control, a form of pain control where the perception of one painful stimulus inhibits the perception of a second painful stimulus for an analgesic effect [11]. All participants were blinded to the intervention others participants received and the expected outcomes.

\subsection{Data Collection}

During the experiment the following measurements were collected pre-intervention and post-intervention for both the control and mindfulness meditation groups:

Anxiety towards pain: This subjective measurement is the degree of anxiety towards pain. Each participant marked the degree of perceived anxiety prior to each cold-pressor task on a line scaled from $0 \mathrm{~mm}$ "no anxiety" to $100 \mathrm{~mm}$ 
"worst anxiety".

Pain Threshold: This objective measurement is the length of time it took for the first sensation of pain after participants submerged their hand in the ice water. Participants stated "pain" verbally on first sensation of pain. The time was recorded using a stop watch.

Pain Tolerance: This objective measurement is the length of time participants were able to keep their hand submerged in the ice water. The time was recorded using a stop watch.

Pain Intensity: This subjective measurement is the degree of perceived pain intensity. Each participant marked the degree of perceived pain intensity on a line scaled from $0 \mathrm{~mm}$ "no pain" to $100 \mathrm{~mm}$ "worst pain" as soon as they removed their hand from the ice water.

Pain Unpleasantness: This subjective measurement is the degree of perceived pain unpleasantness. Each participant marked the degree of perceived pain unpleasantness on a line scaled from $0 \mathrm{~mm}$ "not unpleasant" to $100 \mathrm{~mm}$ "extremely unpleasant" as soon as they removed their hand from the ice water.

\section{Results}

Table 1 lists the descriptive statistics of all the measured variables for both intervention groups. Pre-intervention measures did not differ significantly (all $\mathrm{p}>$ 0.1 ) between intervention groups except for anxiety towards pain ratings. Preintervention anxiety towards pain was significantly higher $(\mathrm{p}<0.05)$ in the mindfulness meditation group compared to the control group. Only pre-intervention pain tolerance times were significantly higher in males compared to females ( $\mathrm{p}<$ 0.05). All other measurements did not differ significantly (all $\mathrm{p}>0.05$ ).

\subsection{Anxiety towards Pain}

Despite the initial difference in anxiety towards pain ratings, repeated-measures analysis of variance (ANOVA) showed a significant main effect for anxiety towards pain across both interventions $(\mathrm{F}(1,22)=10.57, \mathrm{p}<0.01)$. There was also a significant interaction effect for anxiety towards pain $\mathrm{x}$ intervention $(\mathrm{F}(1,22)=$ 6.29, $\mathrm{p}<0.05)$. A paired-sample t-test was conducted for both the control and

Table 1. Descriptive statistics of Cold Pressor task responses and Anxiety towards Pain.

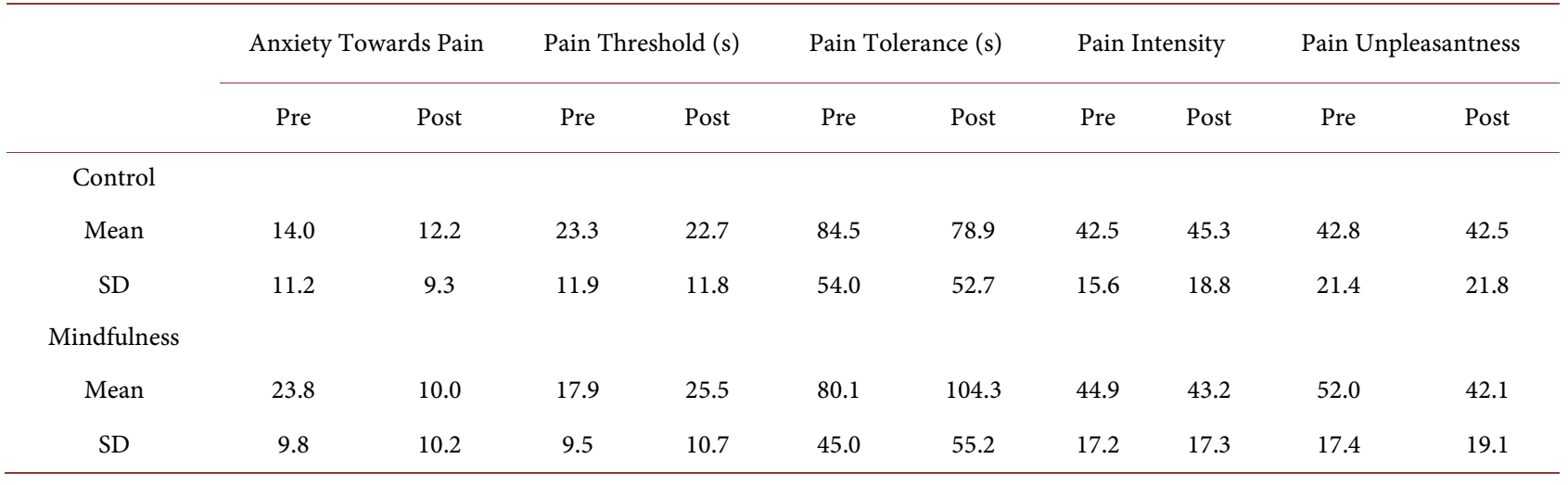


mindfulness meditation group due to the significant interaction effect. A significant decrease $(t(11)=4.07, p<0.005)$ in anxiety towards pain ratings was demonstrated in the mindfulness meditation group. Anxiety towards pain ratings did not change significantly in the control group $(t(11)=0.53, p>0.5)$ (see Figure 1).

\subsection{Pain Threshold and Pain Tolerance}

ANOVA analysis of pain threshold times showed a significant main effect ( $F$ $(1,22)=13.42, \mathrm{p}=0.001)$ and interaction effect for pain threshold $\mathrm{x}$ intervention $(\mathrm{F}(1,22)=18.45, \mathrm{p}<0.001)$. A paired-sample $\mathrm{t}$-test was conducted for both the control and mindfulness meditation group due to the significant interaction effect. A significant increase $(t(11)=-4.38, p=0.001)$ in pain threshold times was demonstrated in the mindfulness meditation group. Pain threshold time did not change significantly in the control group $(t(11)=0.76, p>0.1)$ (see Figure 2).

ANOVA analysis of pain tolerance times showed a significant main effect $(\mathrm{F}(1,22)=7.13, \mathrm{p}<0.05)$ and interaction effect for pain tolerance $\mathrm{x}$ intervention $(\mathrm{F}(1,22)=18.34, \mathrm{p}<0.001)$. A paired-sample $\mathrm{t}$-test was conducted for both the control and mindfulness meditation group due to the significant interaction effect. A significant increase $(t(11)=-4.20, p=0.001)$ in pain tolerance was demonstrated in the mindfulness meditation group. Pain tolerance time did not change significantly in the control group $(\mathrm{t}(11)=1.44, \mathrm{p}>0.1$ ) (see Figure 3 ).

\subsection{Pain Intensity and Pain Unpleasantness}

ANOVA analysis showed there was neither significant main effect nor interaction effect between interventions for both pain intensity and pain unpleasantness.

\section{Discussion}

The results suggest a single 10 minute mindfulness meditation intervention administered by a novice therapist can improve pain tolerance, pain threshold and decrease anxiety towards pain in naive healthy university aged individuals. The findings demonstrate a potential improvement in the ability to cope with a painful experience after brief mindfulness meditation irrespective of the degree of perceived pain intensity or unpleasantness. Ease of application and cost effectiveness of brief mindfulness meditation may also make it a viable alternative analgesic option for a range of pain management situations (i.e. prior to painful rehabilitative activity) and settings (i.e. clinical waiting rooms).

Our results confirmed earlier reports of Zeidan et al. [5] who demonstrated effective reduction of anxiety, pain unpleasantness and pain intensity ratings following a 3 day mindfulness meditation intervention. However, the intervention in the study of Zeidan et al. [5] required a substantial time commitment from participants and training sessions were conducted by an instructor with more than 10 years of trained mindfulness meditation experience. In a later improvement Liu et al. [12] designed a 25-minute mindfulness based training session consisting of 15 minutes of pre-recorded mindfulness meditation instruction, 


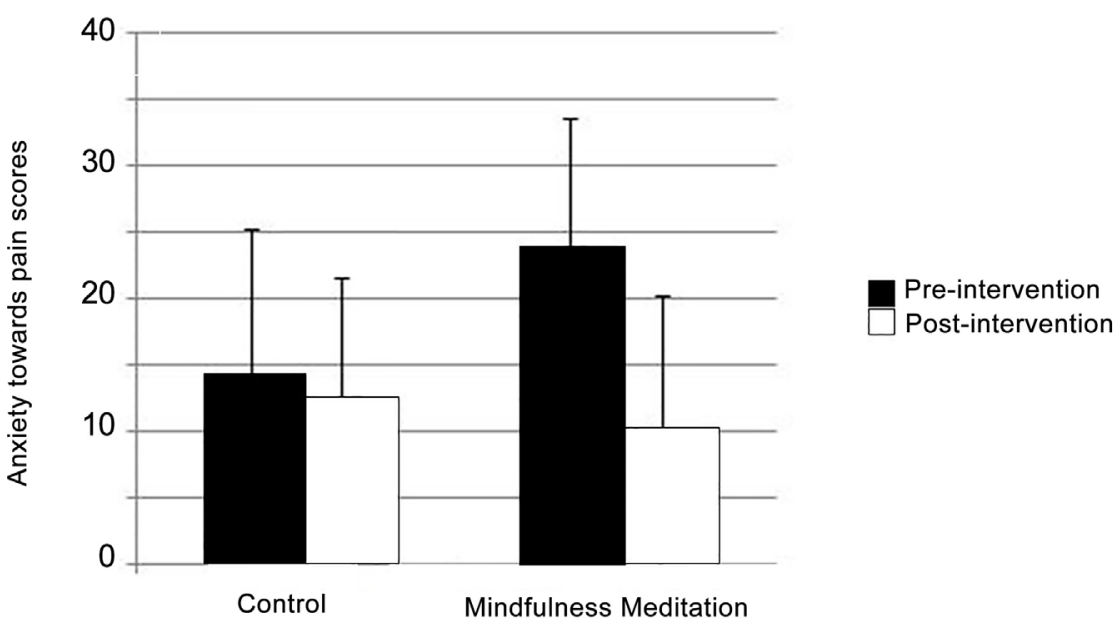

Figure 1. Anxiety towards pain ratings pre-intervention and post-intervention.

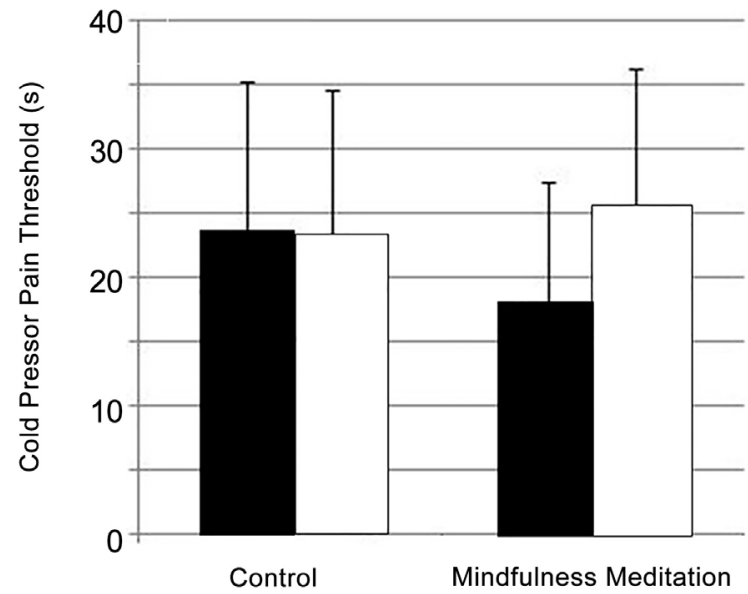

Pre-intervention Post-intervention

Figure 2. Cold Pressor pain threshold times pre-intervention and post-intervention.

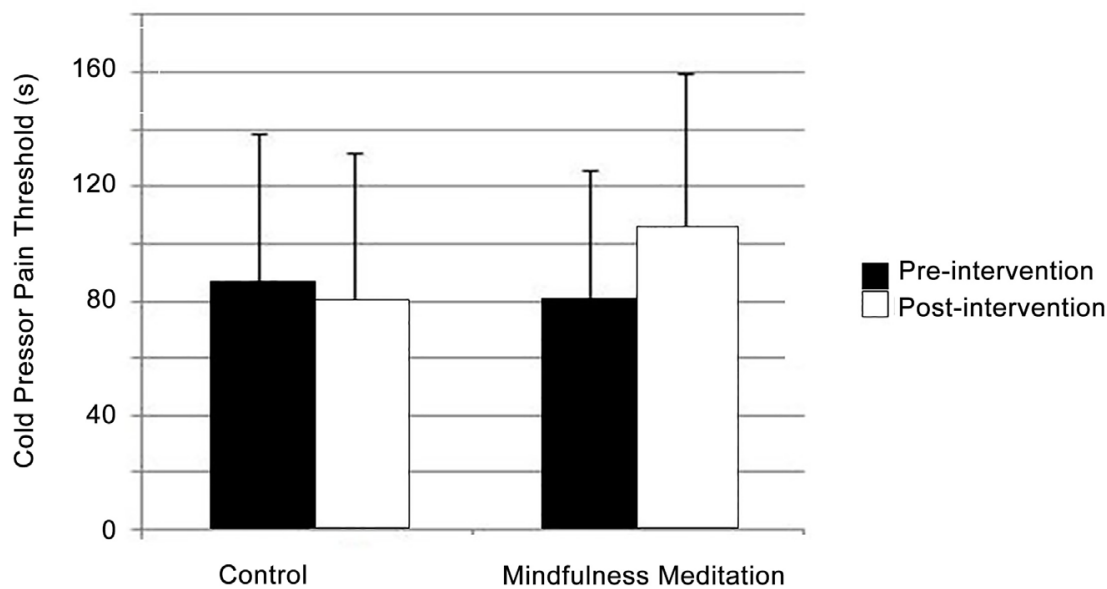

Figure 3. Cold pressor pain tolerance times pre-intervention and post-intervention.

followed by 10 minutes of practice. This brief intervention revealed a significant improvement in pain tolerance and distress ratings $(\mathrm{p}<0.05)$ but no significant difference in pain intensity ratings, partially replicating findings of longer inter- 
ventions [12]. However, only female participants were examined and the study lacked a comparable control group. This intervention also lacked patient-therapist interaction since pre-recorded mindfulness instruction was used.

Clearly, more research is needed to include short mindfulness intervention in the arsenal of pain therapists. The significant results presented here should be approached with caution as the sample size was small and the control group had 10 minutes similar to the intervention group so they may be also had a chance to reflect on their experience. More significantly, all participants were young healthy pain-free students. This research suggested that brief mindfulness intervention can be of benefit in pain relief but should be explored more in clinical setting on chronic pain patients.

\section{Acknowledgements}

Authors wish to thank the Centre for Pain Research at Leeds Beckett University for offering the laboratory to conduct this experiment.

\section{Conflict of Interest}

Authors wish to announce that there has no conflict of interest regarding the conduct and publication of this study.

\section{References}

[1] Reiner, K., Tibi, L. and Lipsitz, J.D. (2013) Do Mindfulness-Based Interventions Reduce Pain Intensity? A Critical Review of the Literature. Pain Medicine, 14, 230242. https://doi.org/10.1111/pme.12006

[2] Hayes, S.C. and Wilson, K.G. (2003) Mindfulness: Method and Process. Clinical Psychology: Science and Practice, 10, 161-165. https://doi.org/10.1093/clipsy.bpg018

[3] Kabat-Zinn, J., Lipworth, L. and Burney, R. (1985) The Clinical Use of Mindfulness Meditation for the Self-Regulation of Chronic Pain. Journal of Behavioral Medicine, 8, 163-190. https://doi.org/10.1007/BF00845519

[4] Rosenzweig, S., Greeson, J.M., Reibel, D.K., Green, J.S., Jasser, S.A. and Beasley, D. (2010) Mindfulness-Based Stress Reduction for Chronic Pain Conditions: Variation in Treatment Outcomes and Role of Home Meditation Practice. Journal of Psychosomatic Research, 68, 29-36. https://doi.org/10.1016/j.jpsychores.2009.03.010

[5] Zeidan, F., Gordon, N.S., Merchant, J. and Goolkasian, P. (2010) The Effects of Brief Mindfulness Meditation Training on Experimentally Induced Pain. The Journal of Pain, 11, 199-209. https://doi.org/10.1016/j.jpain.2009.07.015

[6] Ludwig, D.S. and Kabat-Zinn, J. (2008) Mindfulness in Medicine. Jama, 300, 13501352. https://doi.org/10.1001/jama.300.11.1350

[7] Edens, J.L. and Gil, K.M. (1995) Experimental Induction of Pain: Utility in the Study of Clinical Pain. Behavior Therapy, 26, 197-216.

https://doi.org/10.1016/S0005-7894(05)80102-9

[8] Compton, P., Charuvastra, V.C. and Ling, W. (2003) Effect of Oral Ketorolac and Gender on Human Cold Pressor Pain Tolerance. Clinical and Experimental Pharmacology and Physiology, 30, 759-763. https://doi.org/10.1046/j.1440-1681.2003.03907.x 
[9] Mitchell, L.A., MacDonald, R.A. and Brodie, E.E. (2004) Temperature and the Cold Pressor Test. The Journal of Pain, 5, 233-237. https://doi.org/10.1016/j.jpain.2004.03.004

[10] Shonin, E., Van Gordon, W. and Griffiths, M. (2013) Mindfulness-Based Interventions: Towards Mindful Clinical Integration. Frontiers in Psychology, 4, 194. https://doi.org/10.3389/fpsyg.2013.00194

[11] Alabas, O.A., Tashani, O.A., Tabasam, G. and Johnson, M.I. (2012) Gender Role Affects Experimental Pain Responses: A Systematic Review with Meta-Analysis. European Journal of Pain, 16, 1211-1223. https://doi.org/10.1002/j.1532-2149.2012.00121.x

[12] Liu, X., Wang, S., Chang, S., Chen, W. and Si, M. (2013) Effect of Brief Mindfulness Intervention on Tolerance and Distress of Pain Induced by Cold-Pressor Task. Stress and Health, 29, 199-204. https://doi.org/10.1002/smi.2446

Submit or recommend next manuscript to SCIRP and we will provide best service for you:

Accepting pre-submission inquiries through Email, Facebook, LinkedIn, Twitter, etc. A wide selection of journals (inclusive of 9 subjects, more than 200 journals)

Providing 24-hour high-quality service

User-friendly online submission system

Fair and swift peer-review system

Efficient typesetting and proofreading procedure

Display of the result of downloads and visits, as well as the number of cited articles Maximum dissemination of your research work

Submit your manuscript at: http://papersubmission.scirp.org/

Or contact pst@scirp.org 